
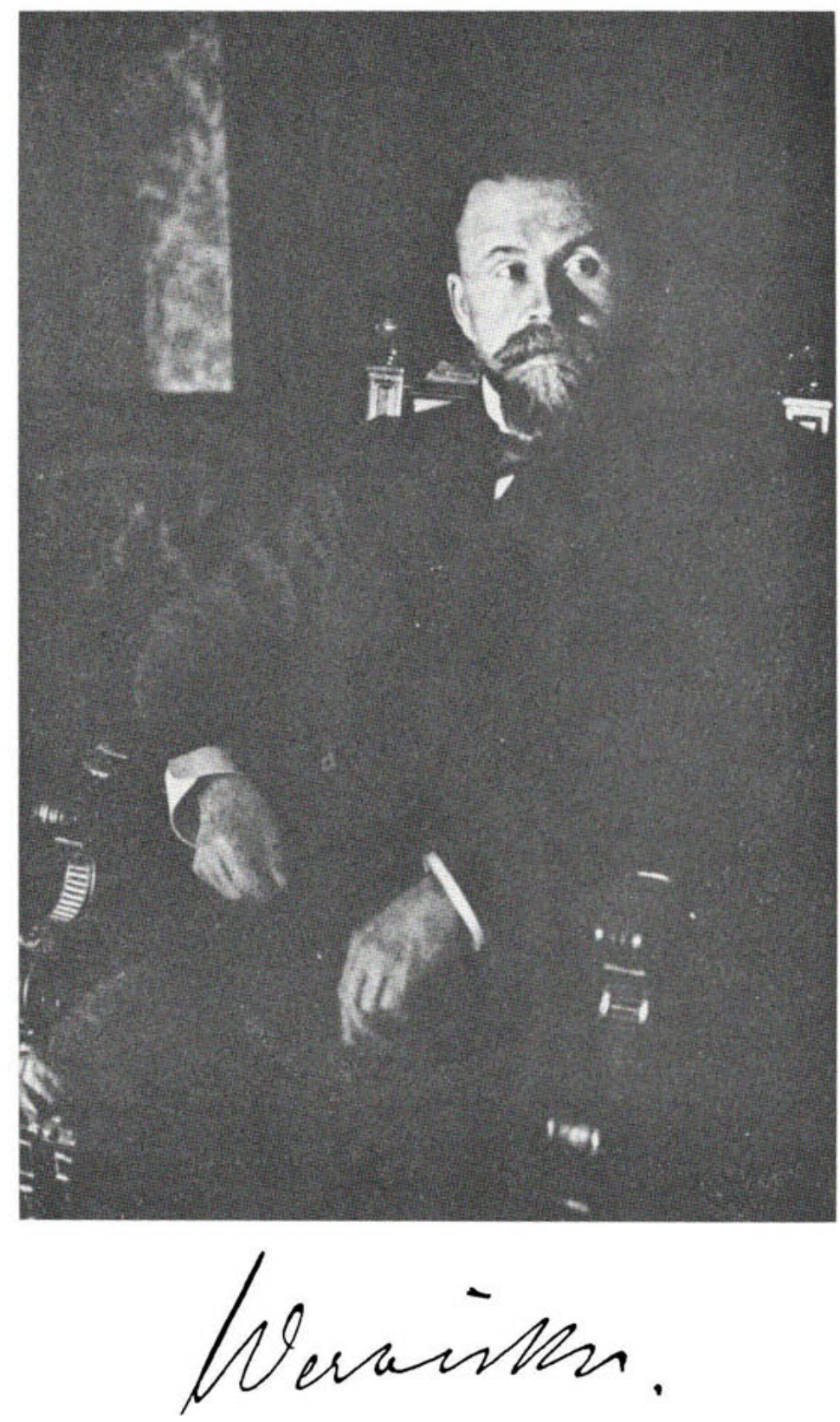

\title{
CARL WERNICKE
}

\author{
1848-1905
}

The publication of Wernicke's epochal Der aphasische Symptomencomplex. Eine psychologische Studie auf anatomischer Basis in 1874 marks the start of the development of a scientific approach to aphasia. 
